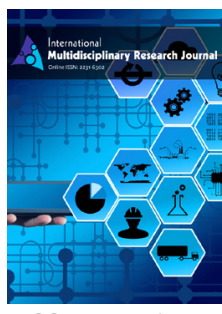

ISSN: $2231-6302$

Received: February 28, 2019

Accepted: April 2, 2019

Published: April 12, 2019

*Corresponding Author:

Ogagaoghene U. Idhalama

Email: idhalamao@gmail.com

\title{
The role of knowledge management for education in Nigeria
}

\author{
Christopher A. Omigie, Iguehi J. Ikenwe, Ogagaoghene U. Idhalama* \\ Department of Library and Information Science, Ambrose Alli University, Ekpoma, Edo State, Nigeria
}

\begin{abstract}
The study investigates the pivotal role of knowledge management within the academic parlance which has a positive spiral and multiplier effects in a given economy by way of taking our dear country from the shackles of hunger, poverty, insecurity etc. It is clear that the effectiveness and efficiency of any organization/economy rest squarely on its level of knowledge: tacit and explicit. However, this knowledge must be critically studied, tapped, stored and disseminated. This study therefore looked at the concept of knowledge, management, its relevance and role in effective academic system and how knowledge management could contribute in taking a country like Nigeria out of the woods.
\end{abstract}

KEYWORDS: Knowledge, knowledge management, education, economy, economic recession

\section{INTRODUCTION}

\section{Overview of Knowledge}

Knowledge has been recognized as a driving force and a vital human resource for productivity, social, educational and economic growth in this $21^{\text {st }}$ century. However, this has given rise to the pursuit for knowledge by corporate individuals, enterprises, organizations and institutions. In this light, it is worthy to state that knowledge is pivotal in all human endeavors and the overall value of knowledge depends on the extent it is shared and used by others. Over the centuries, many Scholars have attempted to define knowledge [1]. Some authors defined knowledge as something that evolves in peoples' minds by a combination of data, information and experiences [2]. In a similar vein, knowledge is the resultant expertise that accumulates and builds up as a person continues to interact, use, practice and experiment with information [3].

However, knowledge are facts, skills, ideas, abilities [know-how], insights and understanding that someone possesses through education, intuition and experience which is deeply understood. Knowledge can be viewed from three perspectives namely; simplistic, subjective and objective view [4]. The simplistic view is used to introduce the concepts of information management which shows the hierarchy from data to wisdom; subjective view presents knowledge as a state of mind in practice. While, objective view advances that knowledge can be discovered, improved upon, stored and transferred [5].

Conceptually, there are two types of knowledge; tacit and explicit knowledge. First one is informal, intuitive, un- codified knowledge, personal knowledge embedded in individuals within an organization, rooted in experience. Such as; expertise, skills, technical know-how etc. It is worthy to note that tacit knowledge represents greater value to an organization and staff should be motivated to share such knowledge through face-face interaction, mentoring, brainstorming, community of best practice etc. Furthermore, valuable tacit knowledge should be identified and converted to codified knowledge since it is a unique asset. Similarly, explicit knowledge is formal and codified. That is, knowledge in written form which can easily be transferred, communicated and stored such as, books, documents, and electronic database etc [Figure 1].

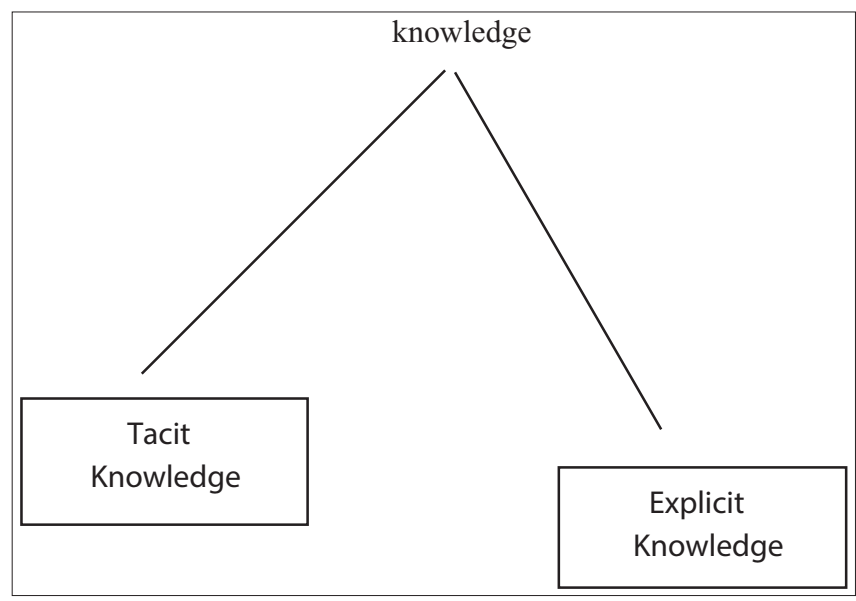

Figure 1: Typology of knowledge

Copyright: (-) The authors. This article is open access and licensed under the terms of the Creative Commons Attribution License (http://creativecommons.org/licenses/by/4.0/) which permits unrestricted, use, distribution and reproduction in any medium, or format for any purpose, even commercially provided the work is properly cited. Attribution - You must give appropriate credit, provide a link to the license, and indicate if changes were made. 


\section{Nature of Knowledge Management (KM)}

Knowledge management is a concept that has emerged explosively in all facets of life in the past decades. The exponential growth of Knowledge management in this knowledge era sprang from the realization that organizational knowledge (especially tacit) is an asset that needs to be nurtured, sustained, shared, improved upon and disseminated across an organization to provide solutions to organizational problems. However, knowledge management has been defined by different scholars. KM is referred to the various techniques and technologies used to organize and build on business expertise and knowledge [5]. The concept of KM has to do with organizing an organizational tacit and explicit knowledge through an organizational and systematic specified process for acquiring and controlling the flow of knowledge of the employees [6]. This is to ensure that organizations achieve their mission and vision statement. KM has three major components. They are: people, process and technology.

According to some authors [7], KM entails:

- Capturing the knowledge that employees and customers need at a central repository

- Identification of the categories of knowledge needed to support the overall business strategy

- Process of collecting, classifying and disseminating information throughout the organization

- Assessment of the current knowledge base of the organization, identify and filling the knowledge gaps

- Employment of IT to help organize and store information

- Provision of access tools

The reasons for KM in organizations are identified below:

- Organizational productivity

- Organizational effectiveness and success

- To promote collaboration and teamwork

- To encourage knowledge sharing

- For better and timely services in organizations

- To enhance innovation

- To protect valuable and useful knowledge from being lost

- To promote attractive work enabling environment

- To promote creativity, critical thinking among employees

- To enhance competitiveness in organization which ensures they are ahead of their competitors by rendering superior services

\section{The Role of Knowledge Management in Effective Academic System}

Knowledge management (KM) as described by [8] is a process of tapping knowledge and putting such into use to encourage learning and organizational productivity. It deals with finetuning and transferring personal knowledge to a corporate knowledge that can be widely disseminated in order to achieve target objectives in learning institutions. Sequel to the above definition, knowledge management is expected to start from the corridor of educational institutions which by extension leads to better teaching, learning and enhanced performance. Knowledge management is needed by teachers at all levels to enable them do their job more effectively, it will expose teachers to have unlimited access to information/knowledge, use/re-use knowledge which brings about total staff development and achieving organizational goals. To this end, [9] explained that knowledge management is the sharing of what we know in any organization we found ourselves. They by extension revealed that it is a name used to mean a collection of actions that any teaching institution can take to obtain best efficiency and effectiveness for the knowledge available to it. It is therefore sad to note that many people think KM can only be reserved for corporate organizations like banks, legal firms, industries e.t.c... but contrary to the aforementioned point, [10 ] submitted that many people think that knowledge management can only be applicable to enterprises like companies.

According to the author, schools are the cradles of innovative knowledge and contain an abundant amount of intangible assets; hence it can be more gratifying for teachers to be adequately aware of what knowledge management entails and practice it to the later.

Schools (most especially higher education institutions HEIs) face many problems in a rapidly dynamic global economy [10]. If we agree that the $21^{\text {st }}$ century economy is mixed with different intellectual challenges, managing knowledge/intellectual assets which is to start from schools will be a positive step in the right direction. Teaching and learning organizations today and in the near future, will experience numerous and intensified external pressure influenced by globalization and the past few decades have brought about pressure on HEIs to respond to global challenges that will place the schools on a better pedestal to perform [11].

\section{Success Factors in the Implementation of Knowledge Management in Academic System}

A previous study [12] points out that knowledge management in schools can help to acquire, manipulate and subsequently consolidate on teacher knowledge, experiences and competencies of teachers. Knowledge management could help experienced teachers transfer their experience to the category of teachers referred to as the less experienced [13].

In order to effectively ensure that knowledge management is adequately implemented in the school setting, there are things to be put in place. [14] highlighted seven dimensions which they also see as knowledge management enablers and activators. They are as tabulated below

\begin{tabular}{ll}
\hline Key dimensions & Description \\
\hline Leadership and support & $\begin{array}{l}\text { Management should as a matter of culture } \\
\text { support organization's KM activities. }\end{array}$ \\
$\begin{array}{l}\text { Technology and } \\
\text { infrastructure }\end{array}$ & $\begin{array}{l}\text { technology utilization and effectiveness of the } \\
\text { organization's IT. }\end{array}$ \\
Acquisition and & There should be will to acquire information and \\
learning & learn from the information so acquired.
\end{tabular}




\begin{tabular}{ll}
$\begin{array}{l}\text { Dissemination and } \\
\text { transfer }\end{array}$ & $\begin{array}{l}\text { Knowledge should be disseminated otherwise it } \\
\text { becomes useless to the organization. } \\
\text { It must be passed across the board. } \\
\text { Application and } \\
\text { exploitation }\end{array}$ \\
\hline People competency & $\begin{array}{l}\text { Teachers should be ready to be proficient in } \\
\text { handling knowledge management. }\end{array}$ \\
Sharing culture & $\begin{array}{l}\text { Teachers are not expected to hoard information } \\
\text { from each other. }\end{array}$ \\
\hline
\end{tabular}

The Choo Sense-Making Knowledge Management Theory Applicable in Schools

The Choo Sense-Making KM Model [16] focuses on SenseMaking, Knowledge Creation and Decision Making Skills.

This theoretical model of knowledge management by [16] is related to the present study because it explains what an organization needs in order to succeed by achieving organizational objectives. It starts with the workers/teachers being aware that whatever information or knowledge generated should make sense, pertinent and salient to the school's ideals. On the other hand, the teachers will explore by looking for new information/knowledge from different sources at their disposal. When the knowledge is already generated or created, teachers must still be careful not to make the mistake of using an inappropriate knowledge for a given task. This means the right knowledge should be used at the right time. In all, it is targeted at making wonderful and right decisions by staff of the school. To [17], knowledge creation (also called knowledge construction) is an important activity in the process of knowledge management in schools. According to Bhatt, knowledge creation is defined as the ability to originate novel and useful ideas and solutions which teaching, learning and research institutions support.

\section{Linking Knowledge Management with National Development}

In business organization, Knowledge Management involves all: individual, team, organization, community and the nation. Actively managing organizational knowledge can stimulate information exchange and innovation through free flow of ideas. As a multidisciplinary field, KM is making the best use of knowledge to achieve organizational performance, competitive advantage, innovation, integration and continuous improvement of the individual, organization, community and the nation. Globally, effective KM is now accepted as a key driving force of processes, products and services. Every day, knowledge is being applied in all industrial sectors across the globe.

Previous report [18] affirms that in a bid to achieve better objectives with effective KM, Knowledge Management should be able to reduce costs to encourage its application.

Effective knowledge management reduces the tendency to repeat mistakes again and again by using more collective and systematic processes. This can drastically improve quality of products and services in organization. The out-put and profit margins of such approach is capable of motivating new ideas for continuous knowledge enhancement in the organization. This will greatly contribute to improve organizational excellence which are:

- Drastically cost reduction

- Provision of opportunity for growth and expansion

- Increasing profitability and value for products and services

- Provision of quick responses demand sand queries

[18] opines that Knowledge simply underpins everything we do. Also, in effective knowledge management, accelerated knowledge creation is the platform for innovation. It provides increasingly smart products and services that are knowledge based. Employees' ability to better collaborate their knowledge will enhance knowledge creation. Ideas can now be turned into innovative products and services much faster.

\section{Knowledge Economy in a World of Economic Recession}

Knowledge economy, in today`s world of deep economic recession, will radically and fundamentally transform economies. To harness, restructure and renew organization for better performance, it must be a commitment based on applying key knowledge strategic asset for higher value using such tool as the World Wide Web. [19] stated that every organization needs to introduce and adopt the best knowledge in order to attract fast and unprecedented development, in prosecuting this, the right decisions, right tools and methods are expected to be applied.

In this rapidly changing world, certain things are certain:

- Leaders of economies, industries, and organizations will always be in need of the most appropriate information and demand for the best knowledge

- Strategies and methods of effective knowledge will always change and also get adjusted but the principles will ever remain

- To survive and remain relevant/successful in the depressed global economy, individuals must be effective and productive in whatever they do.

- Cost inefficiencies occasioned by knowledge gaps and poor knowledge flows must no longer be tolerated in the $21^{\text {st }}$ century.

- Knowledge economy is expected to be all encompassing.

\section{CONCLUSION}

In conclusion, it is our belief that knowledge management is rapidly becoming the most important, largest and sustainable economy tool in the world. Those who fail to understand knowledge management today are risking their future. We predict that effective and remarkable knowledge management will naturally be the mainstream and uncommon way to a successful future growth and development.

\section{REFERENCES}

1. Ikenwe IJ, Igbinovia MO. Influence of knowledge sharing in reducing the spread of HIV/AIDS among adolescents in rural areas in Delta State, Nigeria. Kuwait Chapter of Arabian Journal of Business and 
Management Review. 2015;33(2587):1-4.

2. Kucza, T. Knowledge management process model. Technical research centre of finland. VTT PUBLICATIONS 2001.

3. Uzuegbu CP, Arua U. Understanding the scope and perspectives of information management and knowledge management in Igwe. In: K. N. Igwe, C. O. Nnadozie, A. O. Unagha, C. P. Uzuegbu \& M. M. Naga (Eds.), Fundamentals of knowledge management for the knowledge economy (pp. 32-42). Umuahia: Zeh Communications. 2015.

4. McAdam R, McCreedy S. A critical review of knowledge management models. The Learning Organization. 1999;6(3):91-101.

5. Mutula SM, Mooko NP, Knowledge management. In: Aina LO, Mutula SM, Tiamiyu MA, editors. Information and knowledge management in the Digital age: Concepts, Technologies and African Perspectives. Third World Information Services Limited; 2008.

6. Nonaka I, Takeuchi H. The knowledge-creating company, Oxford University Press, 1995.

7. Frost. Knowledge management. Available athttp://www.knowledge. managementtools.net/2014.

8. Nnadozie CO, Nwosu CC, Ononogbo R U, Nnadozie CD. Typology of knowledge and conceptualization. In Igwe K.N., Nnadozie, C.O., Unagha, A.O., Uzuegbe, C.P. \& Naga, M.M. (Eds.) Fundamentals of knowledge management for the knowledge economy. Zeh Communications-Lagos. 2015.

9. Moballeghi M, Moghaddam GG. Knowledge management and measuring its impact on organisational performance. In: Proceedings of the International Conference on Financial Management and Economics 2011 (Vol. 11).

10. Birgeneau $R$. The role of the university and basic research in the new economy. Jones G, Mccarney P, Skolnik M (2005) Creating Knowledge, Strengthening Nations-The changing role of higher education. 2005:9.

11. Bloom D. Raising the pressure: globalization and the need for higher education reform. Creating Knowledge: Strengthening Nations: The Changing Role of Higher Education, University of Toronto Press, Toronto. 2005:21-41.

12. Zhao J. School knowledge management framework and strategies: The new perspective on teacher professional development. Computers in human behavior. 2010 Mar 1;26(2):168-75.

13. Chu KW, Wang M, Yuen AH. Implementing knowledge management in school environment: Teachers' perception. Knowledge Management \& E-Learning: An International Journal. 2011;3(2):139-52.

14. Rodrigues LLR, Pai R. Preparation and validation of knowledge management measument instrument: an empirical study in educational and IT sectors. In: S. Al-Hawamdeh \& M. International conference on knowledge management (Eds.) knowledge management: nurturing culture, innovation and technology: proceedings of the 2005 international conference on knowledge management, North Carolina, USA, 27 - 28 October 2005 (pp. 582 - 593). Singapore, Hackensack, N.J; world scientific.

15. Wei Choo C. Working with knowledge: how information professionals help organisations manage what they know. Library Management. 2000;21(8):395-403.

16. Wei Choo C. The Knowing Organisation: how Organisations Use Information to Construct Meaning Create Knowledge and Make Decisions. Oxford university press, New York. NY.

17. Bhatt GD. Knowledge management in organizations: examining the interaction between technologies, techniques, and people. Journal of Knowledge Management. 2001;5(1):68-75.

18. Ron Y. Why KM- the Importance of Knowledge Management. Knowledge-Management-oline.com. 2005.

19. Roknuzzaman M, Umemoto K. How library practitioners view knowledge management in libraries: A qualitative study. Library Management. 2009;30(8/9):643-56. 